\title{
Effect of Plasma Cleaning on Fluxless Plasma Soldering of Pb-free Solder Balls on Si-wafer
}

\author{
Joon Kwon Moon ${ }^{1}$, Kyung In Kang ${ }^{1}$, Jae Pil Jung ${ }^{1}$ and Yun Hong Zhou ${ }^{2}$ \\ ${ }^{1}$ Department of Materials Science and Engineering University of Seoul, Seoul 130-743, Korea \\ ${ }^{2}$ Department of Mechanical Engineering University of Waterloo, Waterloo, N2L 3G1, Canada
}

\begin{abstract}
An $\mathrm{Ar}-10 \mathrm{vol} \% \mathrm{H}_{2}$ plasma was applied as a cleaning medium on UBMs (Under Bump Metallizations) to improve the bondability of solder balls prior to plasma reflow. Each UBM area comprised four layers deposited on a Si-wafer. Sequentially, the deposit comprised $0.4 \mu \mathrm{m}$ of Al, $4 \mu \mathrm{m}$ each of $\mathrm{Ni}$ and $\mathrm{Cu}$, and $20 \mathrm{~nm}$ of $\mathrm{Au}$ from bottom to top of the metallization. Two compositions of lead-free solder balls (Sn-3.5 mass \% Ag and $\mathrm{Sn}-3.5$ mass\%Ag-0.7 mass\%Cu) and a lead containing one (Sn-37 mass\% $\mathrm{Pb}$ ) as a reference were selected for the experiment. The solder balls, of $500 \mu \mathrm{m}$ diameter, were placed on the UBM's and fluxlessly soldered under $\mathrm{Ar}-10 \% \mathrm{H}_{2}$ plasma (with or without prior plasma cleaning). Additionally, air reflow with flux was also performed for comparison. Experimental results showed that the spreading ratios of the solders by plasma reflow after plasma cleaning were $20-40 \%$ higher than those plasma reflowed without cleaning. The shear strengths of the solder balls processed by the plasma-cleaned plasma reflow showed around $58-65 \mathrm{MPa}$, which is $60-80 \%$ and $15-35 \%$ higher than that of plasma reflow without plasma cleaning, and that of fluxed air reflow, respectively. From this study, plasma cleaning of UBM's using Ar- $10 \% \mathrm{H}_{2}$ gas was shown to be quite effective to improve the bond strength of solder balls.
\end{abstract}

(Received January 6, 2004; Accepted April 19, 2004)

Keywords: plasma cleaning, lead-free solder, fluxless plasma soldering, microstructure, joint strength

\section{Introduction}

Environmentally benign materials and processes in soldering for electronics are now being actively pursued by many investigators. Lead $(\mathrm{Pb})$-free solders ${ }^{1,2)}$ and fluxless soldering processes ${ }^{3-6)}$ can be important components in technology improvement. Preferred lead-free solder compositions are usually from the $\mathrm{Sn}-\mathrm{Ag}-\mathrm{Cu}$ alloy system, but there are many obstacles on the way to a flux-free process. Although the flux plays important roles such as oxide removal and wetting improvement of the solder, it leaves a harmful residue after soldering. This residue can cause problems like corrosion and reduction of electric insulation resistance in the joint area. ${ }^{7,8)}$ Therefore, the residue is very undesirable on opto-electronic and fine-pitched electronic devices like flip chips.

Some processes for fluxless soldering have been introduced: fluxless soldering after plasma cleaning ${ }^{4-9)}$ appears to be a useful approach. Plasma treatment was reported to be effective for removal of oxide from the metal surface, and improvement of solderability. ${ }^{9)} \mathrm{Ar}^{+}$ion sputtering of a $\mathrm{Ni}$ layer plated on a metal substrate was also shown to yield a decrease in interfacial voids in subsequent $\mathrm{Pb}-\mathrm{Sn}$ solder joints. ${ }^{10)}$ Other studies of plasma treatment using $\mathrm{O}_{2}$, Ar and $\mathrm{Ar}-\mathrm{H}_{2}$ gas have shown improvement of the strength of wire bonds and the adhesion of a molding compound to a solder mask in PBGA (Plastic Ball Grid Array). ${ }^{11)}$ In addition, the plasma cleaning also increased wettability of de-ionized water on Au die-pads. Conversely, other researchers such as Yang et al. ${ }^{12)}$ found that the ball shear strength of bonding wires was not improved by plasma cleaning, and no improvement was seen on the interface of die attach and substrate. However, they did find enhancement of adhesion strength between a molding compound and substrate by plasma cleaning. From these studies, during plasma reflow the effect of plasma cleaning on the wetting and reaction of solder and on the bonding strength of solder balls has not been sufficiently clarified.

In the authors' previous studies, ${ }^{9,13)}$ the $\mathrm{Ar}-\mathrm{H}_{2}$ plasma gas showed possibilities for fluxless soldering in terms of cleaning and reflowing methods. In detail, plasma cleaned solder bumps were fluxlessly soldered in air, but the bond strength was not adequate. ${ }^{9)}$ As a solution, soldering under an inert atmosphere was suggested to avoid reoxidation. In the following study, ${ }^{13)}$ plasma heating during reflow provided a non-oxidizing inert atmosphere, however the bond strength only reached about half of the level produced by fluxed air reflow. The lower strength was caused by the exhaustion of UBM (Under Bump Metallization) under the high soldering temperature of plasma, hence a thicker UBM comprising $4 \mu \mathrm{m}$ each of $\mathrm{Cu}$ and $\mathrm{Ni}$ was prepared, and this resulted in better strength, to $85 \%$ of air reflow.

In the present work, to provide the best possible conditions for fluxless plasma soldering, $\mathrm{Ar}+10 \% \mathrm{H}_{2}$ plasma cleaning was applied to UBM's prior to the plasma reflow. Building upon the previous results, ${ }^{9,13)}$ the plasma cleaning and the plasma reflow were applied to the thick UBM.

\section{Experimental}

A UBM coated Si-wafer was prepared as a substrate for each soldering specimen. The UBM consisted of $0.4 \mu \mathrm{m}$ of $\mathrm{Al}, 4 \mu \mathrm{m}$ each of $\mathrm{Ni}$ and $\mathrm{Cu}$, and $20 \mathrm{~nm}$ of $\mathrm{Au}$, sequentially from bottom to top of the metallization, (Fig. 1). The UBM layers were deposited by thermal (for the $\mathrm{Al}$ layer) and electron-gun evaporation (for the Au layer), but electroplating for the $4 \mu \mathrm{m}$-thick $\mathrm{Cu}$ and $\mathrm{Ni}$ layers. The area of each UBM for solder bumping was $300 \mu \mathrm{m}$ in diameter, and the surrounding metallization was masked by a Ti layer to serve as a dam against molten solder.

Two kinds of UBM preparations were used, one as deposited and the other as plasma cleaned. The plasma cleaning, for the purpose of improving bondability of molten solder on the UBM, was carried out under $\mathrm{Ar}-10$ vol\% $\mathrm{H}_{2}$ 


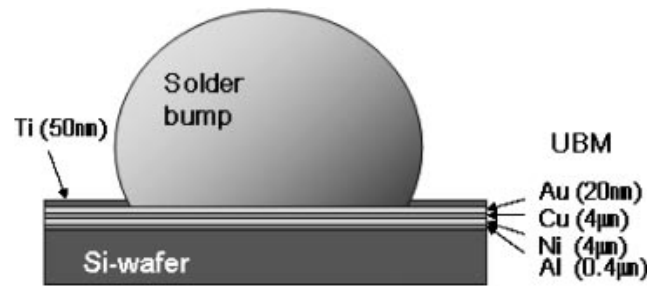

Fig. 1 Schematic illustration of the soldering specimen with UBM layers.

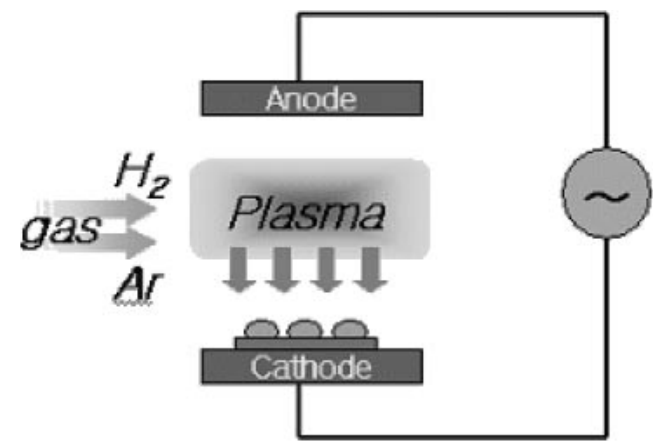

Fig. 2 Schematic illustration of the plasma soldering process.

atmosphere at the power of RF $100 \mathrm{~W}$ for $30 \mathrm{~s}$ (Fig. 2). The pressure in the chamber under plasma was $48 \mathrm{~Pa}$.

Three kinds of solder balls with different compositions but the same size of $500 \mu \mathrm{m}$ diameter were placed on the UBMcoated wafers, including two lead-free solders of compositions Sn-3.5 mass \% Ag, Sn-3.5 mass \%Ag-0.7 mass $\% \mathrm{Cu}$, and the lead-containing $\mathrm{Sn}-37$ mass $\% \mathrm{~Pb}$ as a reference.

The solder balls mounted on each UBM were heated to the soldering temperature under $\mathrm{Ar}-10 \mathrm{vol} \% \mathrm{H}_{2}$ plasma without flux. The heating condition of plasma reflow was $150 \mathrm{~W}-60 \mathrm{~s}$. and the soldering temperature was measured as $593 \mathrm{~K}$ (Fig. 3).

As a reference, hot air reflow soldering with RMA (Rosin Mildly Activated)-flux (hereafter called as air reflow) was also performed in an IR (Infra-Red) oven using the same specimen design. The oven had a conveyor system with 4 heating zones. The soldering temperatures were determined as $523 \mathrm{~K}$ for $\mathrm{Sn}-3.5 \mathrm{mass} \% \mathrm{Ag}$ and $\mathrm{Sn}-3.5 \mathrm{mass} \% \mathrm{Ag}$ 0.7 mass $\% \mathrm{Cu}$, and $503 \mathrm{~K}$ for $\mathrm{Sn}-37$ mass $\% \mathrm{~Pb}$ considering

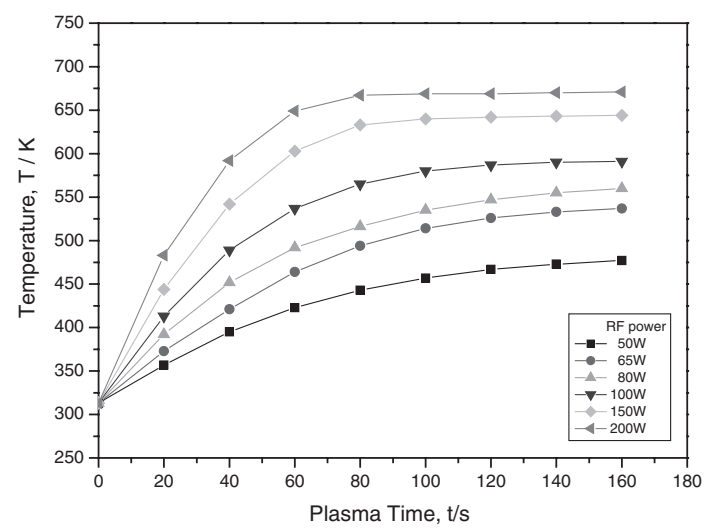

Fig. 3 Temperature of the UBM with heating time in $\mathrm{Ar}-10 \% \mathrm{H}_{2}$ plasma at $150 \mathrm{~W}$ RF power.
Table 1 Soldering conditions for the experiments.

\begin{tabular}{|c|c|c|c|}
\hline \multirow{2}{*}{$\begin{array}{l}\text { Soldering } \\
\text { method }\end{array}$} & \multicolumn{3}{|c|}{ Soldering conditions } \\
\hline & $\mathrm{Sn}-37$ mass $\% \mathrm{~Pb}$ & $\mathrm{Sn}-3.5 \mathrm{mass} \% \mathrm{Ag}$ & $\begin{array}{l}\mathrm{Sn}-3.5 \mathrm{mass} \% \mathrm{Ag}- \\
0.7 \text { mass } \% \mathrm{Cu}\end{array}$ \\
\hline $\begin{array}{c}\text { Air reflow } \\
\text { (with RMA-flux) }\end{array}$ & $\begin{array}{l}\text { Temp.: } 503 \mathrm{~K} \\
\text { Conveyor speed: } \\
0.6 \mathrm{~m} / \mathrm{min} .\end{array}$ & \multicolumn{2}{|c|}{$\begin{array}{l}\text { Temp.: } 523 \mathrm{~K} \\
\text { Conveyor speed: } \\
0.6 \mathrm{~m} / \mathrm{min} .\end{array}$} \\
\hline $\begin{array}{c}\text { Plasma } \\
\text { reflow } \\
\text { (without flux) }\end{array}$ & \multicolumn{3}{|c|}{$\begin{array}{c}\text { Plasma gas: Ar- } 10 \mathrm{vol} \% \mathrm{H}_{2} \\
\text { RF power: } 150 \mathrm{~W} \\
\text { Dwelled time: } 60 \mathrm{~s}\end{array}$} \\
\hline
\end{tabular}

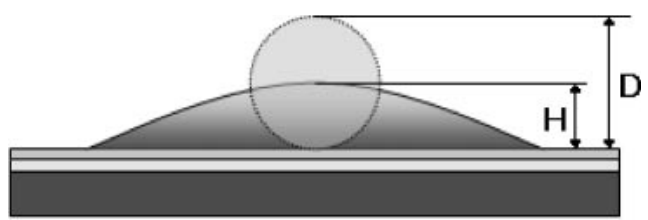

Fig. 4 Schematic illustration of the spreading ratio test.

their melting points of $494 \mathrm{~K}, 490 \mathrm{~K}$, and $456 \mathrm{~K}$, respectively. Experimental conditions for the plasma and the air reflow soldering are summarized in Table 1.

The spreading ratios of solder balls on the UBM were measured to estimate the feasibility of the plasma cleaning process. The spreading test specimens had the same UBM as that of Fig. 1 but each ball was mounted on an open area of square shape, $10 \times 10 \mathrm{~mm}$. Heating conditions of the test specimens were the same as Table 1 for each solder. The spreading ratio $(S)$ was defined as $S=100(D-H) / D(\%)$, where $D$ indicates diameter of solder ball and $\mathrm{H}$, height of solder after spreading ${ }^{14)}$ (Fig. 4).

The solder bumps on the $\mathrm{Si}$-wafers were shear tested using a micro-shear tester, and 20 identical tests were performed and averaged for each soldering condition. The clearance between the shearing tip and the Si-substrate was $10 \mu \mathrm{m}$, and shearing speed was $200 \mu \mathrm{m} / \mathrm{s}$. The sheared areas were measured by an image analyzer, and the shear strength was determined from the area and maximum shear force.

Bulk solder around the interface was removed by chemical etching to observe the IMC (Intermetallic Compounds) formed during solder reflow. Both the bond interfaces of the joint cross-sections and the fractured surfaces of the shear tested specimens were examined by SEM (Scanning Electron Microscopy) and EDS (Energy Dispersive Spectroscopy).

\section{Results and Discussion}

\subsection{Spreading and bonded interfaces}

The Ar- 10 vol $\% \mathrm{H}_{2}$ plasma, previously shown as effective to remove oxide from solder surfaces, ${ }^{9)}$ was used as the cleaning and reflowing atmosphere for all fluxless processing. The appearances of Sn-3.5 mass\% Ag solder bumps, reflowed by Ar-vol10\% $\mathrm{H}_{2}$ plasma (without flux and nonplasma cleaning) and by IR in air (with flux), are compared in Fig. 5. All of the different solder compositions and surface conditions produced bumps of surface appearance similar to those shown in Fig. 5, after reflow. With both reflow processes the bumps showed good shapes, and the plasma 


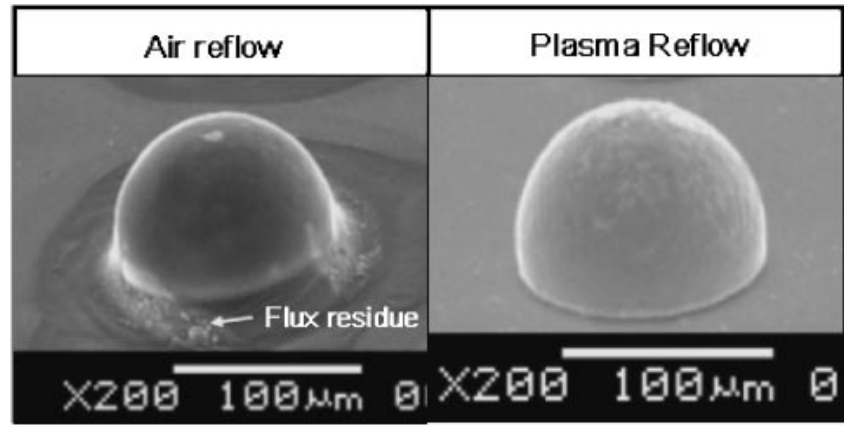

Fig. 5 Sn-3.5Ag solder bumps formed by air reflow with flux and by Ar$10 \% \mathrm{H}_{2}$ plasma reflow without flux.

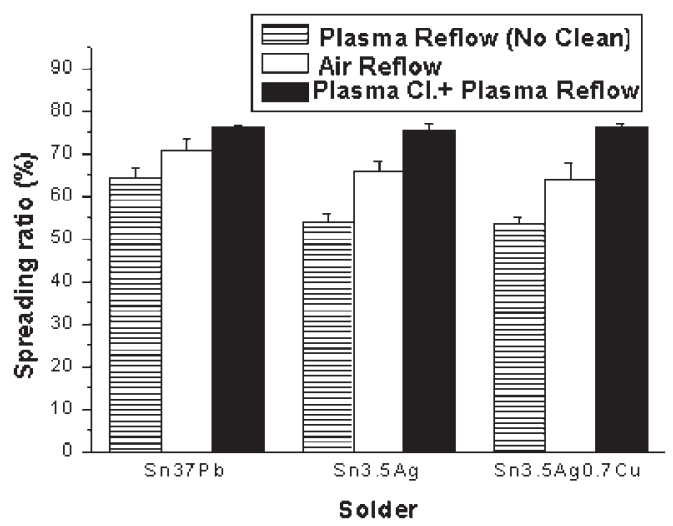

Fig. 6 Comparison of spreading ratios of solders with soldering processes.

soldered ones showed a clear appearance without any visible contaminants. However, in the case of air reflow, the flux residue (that can be a source of pollution or corrosion to an electronic device ${ }^{7,8)}$ was found around the periphery of the bumps.

The spreading ratios of the solders on the UBMs are compared in Fig. 6. The spreading ratios were $75-76 \%$, 64$70 \%$ and $53-64 \%$ for the plasma-cleaned plasma reflow specimens (hereafter called as PC plasma reflow), air reflow and plasma reflow without plasma cleaning (hereafter NC plasma reflow), respectively. Since the plasma cleaning was previously shown as effective to remove oxide and contaminants from a solid surface, ${ }^{10,15)}$ it was expected to improve the spreadability. Lee et al. ${ }^{11)}$ also reported that the cleaning of $\mathrm{Au}$ die-pads by $\mathrm{Ar}, \mathrm{Ar} / \mathrm{H}_{2}$ and $\mathrm{O}_{2}$ plasma increased the wettability of de-ionized water on the pads. Thus, the results shown in Fig. 6 confirmed the positive effects of the plasma cleaning on the solder spreadability during plasma reflow.

From the results of the NC plasma reflow, it was verified that plasma reflow only without prior plasma cleaning is insufficient to get good spreadability. This conclusion can be readily drawn from the difference in plasma cleaning effect between pre-soldering cleaning (corresponding to the PC plasma reflow) versus only during-soldering cleaning (corresponds to the NC plasma reflow). In other words, in presoldering cleaning the whole UBM is exposed directly to the plasma bombardment. However, in plasma reflow without prior cleaning, the shadow area on the UBM under the solder ball is not exposed directly to the plasma bombardment and remains in an incompletely cleaned state. From previous study, $\left.{ }^{9}\right)$ it was shown that the plasma cleaned UBM (i.e. directly exposed to the plasma bombardment) showed about $3 \%$ oxygen on the surface, whereas the non-plasma cleaned one showed around $26 \%$ oxygen by AES analysis with $30 \mathrm{~s}$ sputtering. Therefore, pre-soldering cleaning is evidently much more effective. Moreover, in the PC plasma reflow, cleaning occurs not only prior to soldering but also during soldering. These arguments are believed to fully explain the higher spreadability of solders under the PC plasma process.

The bonded interfaces after plasma reflow were compared to those of the air reflowed specimens in Fig. 7. In terms of the soldering processes, the PC plasma reflow and the air reflow had good bonded interfaces with uniformly formed IMCs. In the case of NC plasma reflow, however, IMCs were not observed in some areas. This confirmed that the molten solder didn't wet well on such areas due to incomplete cleaning, and the solder was unable to react with them.

In the previous study of NC plasma reflowed specimens with thin UBM such as $0.4 \mu \mathrm{m}$ of $\mathrm{Ni}$ and $\mathrm{Cu}$ in each layer, cracks were found between IMCs and the UBM. ${ }^{13)}$ The reason for the cracks was the exhaustion of UBM layers by the excessive reaction with solder under high temperature $(593 \mathrm{~K})$ of plasma processing. Thus, the thickness of UBM had been increased from 0.4 to $4 \mu \mathrm{m}$ to avoid the cracks. ${ }^{13)}$ From Fig. 7, in the PC plasma reflow, interfacial cracks were not observed in any of the specimens. This indicates that the UBM was not exhausted by the additional plasma treatment (i.e. plasma cleaning), and the $4 \mu \mathrm{m}$-thickness UBM was shown to be safe for undergoing successive plasma cleaning and plasma reflow.

The interfacial IMCs produced by PC plasma reflow as shown in Fig. 7 were analyzed by EDS. The compositions in atomic percentages were $49 \mathrm{Sn}, 51 \mathrm{Cu} ; 48 \mathrm{Sn}, 52 \mathrm{Cu}$, and 49 $\mathrm{Sn}, 51 \mathrm{Cu}$ for $\mathrm{Sn}-37 \mathrm{mass} \% \mathrm{~Pb}, \mathrm{Sn}-3.5 \mathrm{mass} \% \mathrm{Ag}$ and Sn3.5 mass $\% \mathrm{Ag}-0.7$ mass $\% \mathrm{Cu}$, respectively. In general the IMC of $\mathrm{Cu}_{6} \mathrm{Sn}_{5}$, produced between Cu-pad and Sn-based solder, needs much less activation energy to form than $\mathrm{Cu}_{3} \mathrm{Sn}$ (e.g. 409 and 1536 (unitless) for $\mathrm{Cu}_{6} \mathrm{Sn}_{5}$ and $\mathrm{Cu}_{3} \mathrm{Sn}$ in $\mathrm{Sn}-$ 3.5 mass $\% \mathrm{Ag} /-0.7$ mass $\% \mathrm{Cu}$, respectively) and more driving force (e.g. 0.31 and $0.18 \mathrm{~J} / R T$ ( $R$; universal gas constant, $T$; absolute temperature) for $\mathrm{Cu}_{6} \mathrm{Sn}_{5}$ and $\mathrm{Cu}_{3} \mathrm{Sn}$ in $\mathrm{Sn}-3.5$ mas$\mathrm{s} \% \mathrm{Ag} /-0.7$ mass $\% \mathrm{Cu}$, respectively. ${ }^{16)}$ Considering these chemical analyses, the activation energy and results of other research, ${ }^{17-20)}$ the interfacial IMCs from the different solders are believed to be all of the same kind, i.e., $\mathrm{Cu}_{6} \mathrm{Sn}_{5}$. The interfacial IMCs produced by air reflow and by NC plasma reflow for the $\mathrm{Sn}-37$ mass $\% \mathrm{~Pb}$ solder were 51 at $\% \mathrm{Sn}$, 49 at $\% \mathrm{Cu}$ and 52 at $\% \mathrm{Sn}, 48$ at $\% \mathrm{Cu}$, respectively. Comparing this to the IMCs from PC plasma reflow, evidently the IMCs from all three processes can be regarded as the same. Furthermore, the lack of $\mathrm{Ni}$ in these IMCs has verified that the UBM layer thicknesses were sufficient to avoid $\mathrm{Cu}$ layer exhaustion.

\subsection{Shear bond strength and fracture surfaces}

Shear bond strengths of the solder balls with various soldering processes are listed in Fig. 8. In the case of NC plasma reflow, the strength averages varied from 32 to $42 \mathrm{MPa}$ with the three solders. However, the PC plasma 


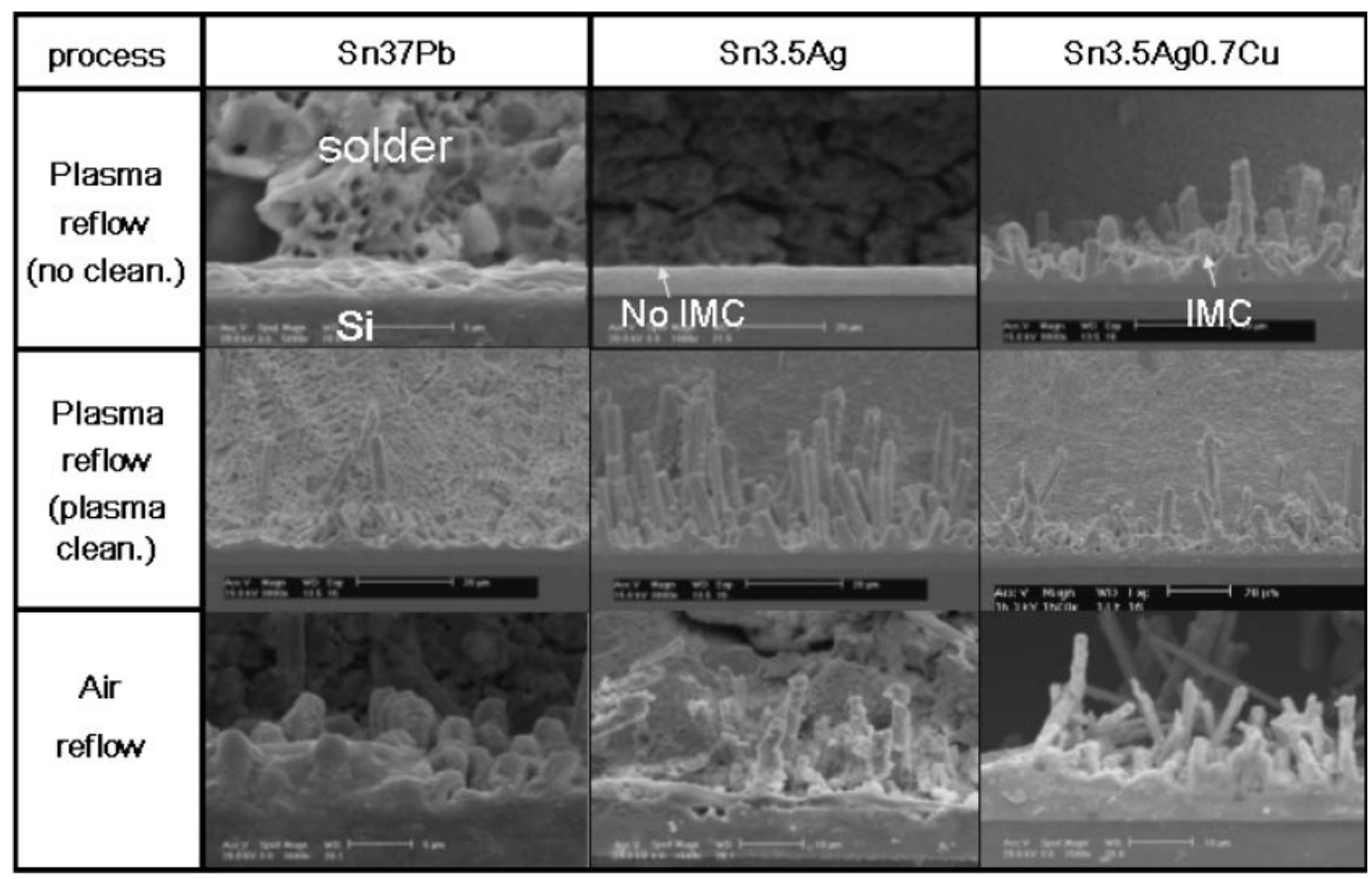

Fig. 7 Bonded interfaces between solders and UBM coated Si-substrate with soldering processes.

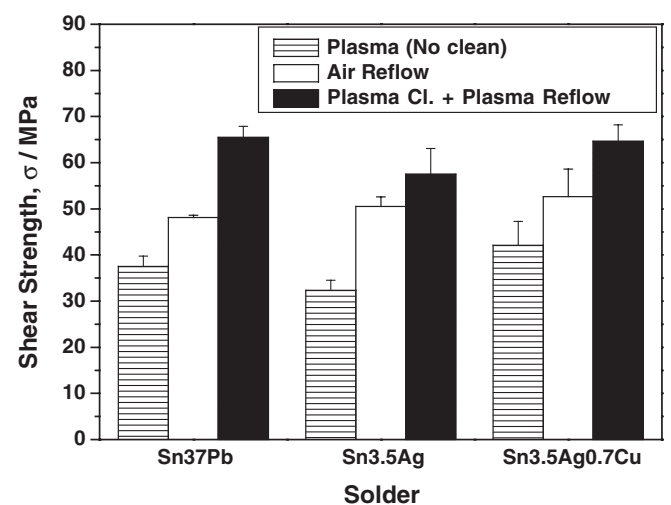

Fig. 8 Comparison of shear strength of solder balls with soldering processes.

reflow showed around 58-65 MPa, and the air reflow yielded 48-50 MPa. This result implies that, by applying plasma cleaning prior to plasma reflow, the bond strength increased by about $60-80 \%$. Thus, further confirmation was obtained that the plasma cleaning using $\mathrm{Ar}-10 \mathrm{vol} \% \mathrm{H}_{2}$ prior to reflow was effective for improving bond strength of reflowed joints.

The fracture surfaces of the shear tested specimens (substrate side) are illustrated in Fig. 9. The PC plasma reflow specimens showed fracture occurring across the solder, and no partial fractures along the UBM were found with any solder. In the case of NC plasma reflow, however, partial fracture along the UBM (for instance, the location marked ' $\mathrm{D}$ ' in $\mathrm{Sn}-37$ mass\% $\mathrm{Pb}$ ) was observed. The lack of interfacial fractures with PC plasma reflow further confirms the effective removal of oxide and contaminant from the UBM and solder joint during plasma cleaning., $\left.{ }^{9}, 15,21\right)$ The partial interfacial fracture produced by insufficient bonding clearly explains the lower average shear strength of the NC plasma reflow specimens. The beneficial effect of Ar$10 \mathrm{vol} \% \mathrm{H}_{2}$ plasma cleaning also reflects the results from other studies such as increase of the bond strength of wire bump $^{11)}$ and the adhesion strength of molding compound ${ }^{12)}$ by plasma cleaning.

In Fig. 8, the PC plasma reflow showed 15-35\% higher strength than that of air reflow specimens as well. Through fracture surface examination, the reason why the air reflow specimens have lower strength was clarified. Solder joints made with air reflow have a flux residue as shown in Fig. 5. On the bonded interface, the presence of flux means that the air reflow joints have higher possibility of having a defect like a void. Figure 10 shows voids found on the bonded interface and on the fracture surface of the air reflowed Sn3.5 mass $\%$ Ag- 0.7 mass $\%$ Cu. During the air reflow, volatile materials from the flux and contaminants on the UBM surface will vaporize. These volatile materials can make voids, leading to inadequate interfacial strength. ${ }^{21)}$ Conversely, in joints made with plasma cleaning and without flux, contaminants on the solid surface can change into volatile materials and be evacuated by the pumping system before the solder melts and covers the surface. ${ }^{15)}$ Furthermore, the plasma gas can penetrate into very small sites where liquid flux cannot penetrate. Therefore, plasma cleaning can lead more easily to a void-free and hence a stronger joint. ${ }^{10)}$

\section{Conclusions}

A cleaning process using $\mathrm{Ar}-10 \mathrm{vol} \% \mathrm{H}_{2}$ plasma was applied to UBMs on Si wafers to improve the bond strength of reflowed solder balls. The UBM consisted of $0.4 \mu \mathrm{m}$ of $\mathrm{Al}$, $4 \mu \mathrm{m}$ each of $\mathrm{Ni}$ and $\mathrm{Cu}$, and $20 \mathrm{~nm}$ of $\mathrm{Au}$, sequentially from bottom to top of the metallization. Two compositions of lead- 


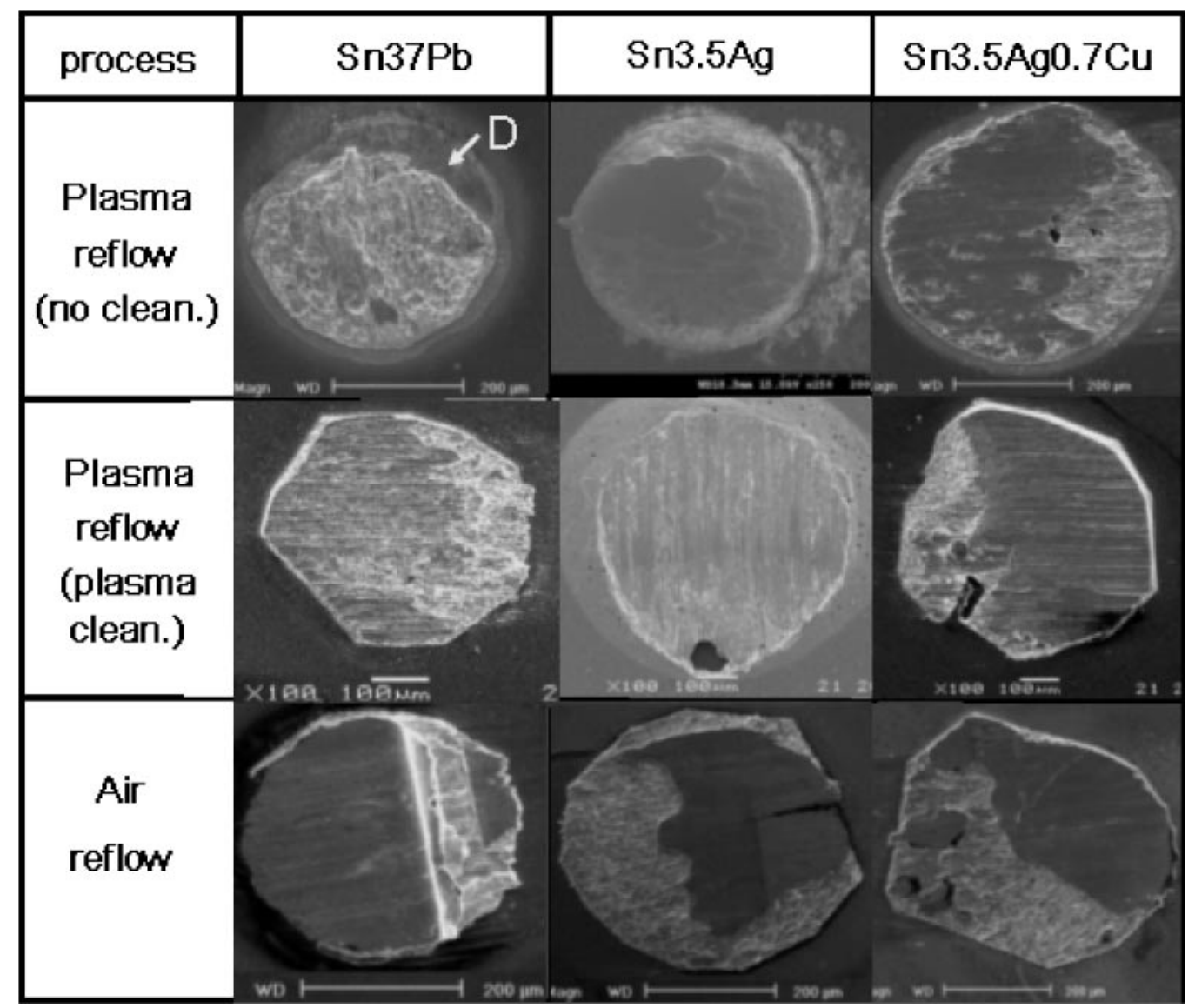

Fig. 9 Fracture surfaces of shear tested specimens with reflow processes and solders.

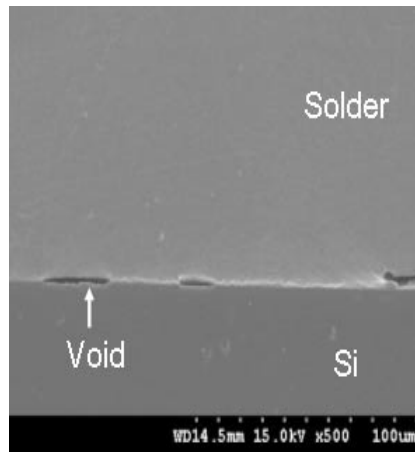

(a)

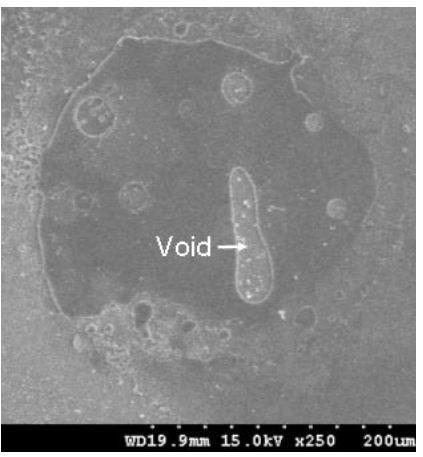

(b)
Fig. 10 Voids observed on the bonded interface (a), and on the fracture surface (b) of Sn-3.5Ag-0.7Cu soldered by air reflow with flux.

free solder balls: Sn-3.5 mass\%Ag and Sn-3.5 masst\%Ag0.7 mass $\% \mathrm{Cu}$, and the conventional $\mathrm{Sn}-37 \mathrm{mass} \% \mathrm{~Pb}$ for a reference, were reflow soldered under $\mathrm{Ar}-10$ vol $\% \mathrm{H}_{2}$ plasma without flux. Air reflow with flux was also carried out with the same alloys as a reference. The main results can be summarized as follows.

(1) Plasma cleaning was quite effective to enhance the bondability of solder balls. By application of the plasma cleaning, the shear strength of the solder balls by plasma reflow (PC plasma reflow) improved greatly, reaching $58-65 \mathrm{MPa}$, which is $60-80 \%$ and $15-35 \%$ higher than the results for plasma reflow without plasma cleaning (NC plasma reflow) and those for air reflow, respectively.

(2) The spreading ratio of solders processed by PC plasma reflow reached about $75 \%$, whereas $53-64 \%$ was found for the NC plasma reflow specimens, and $64-70 \%$ for the air reflow specimens with flux.

(3) The PC plasma reflow specimens showed crack-free bonded interfaces, and it was confirmed that the $4 \mu \mathrm{m}$ thickness UBM was adequate for undergoing both plasma cleaning and plasma reflow.

(4) The improvement in joint strength by use of the PC plasma processing route is believed to result from more effective cleaning compared to NC plasma reflow processing, and from lack of voids on the interface compared to the air reflow.

\section{Acknowledgements}

This is the result from the research professor program in 2003 by the support of University of Seoul in Korea, and the authors appreciate for the support.

\section{REFERENCES}

1) M. R. Harrison, J. H. Vincent and H. A. H. Steen: Solder. \& Surf. Mont. Tech. 13 (2001) 21-38.

2) A. Z. Miric and A. Grusd: Solder. \& Surf. Mont. Tech. 10 (1998) 19- 
25.

3) R. J. K. Wassink: Soldering in Electronics, (Electrochemical Pub. Ltd., 1984) 34.

4) G. Takyi, N. N. Ekere and J. D. Philpott: J. Electro. Manufact. 9 (1999) 233-239.

5) S. M. Hong, C. S. Kang and J. P. Jung: Mater. Trans. 43 (2002) 13361340.

6) C. B. Park, S. M. Hong, J. P. Jung, C. S. Kang and Y. E. Shin: Mater. Trans. 42 (2001) 820-824.

7) L. Zou, M. Dusek, C. P. Hunt and B. D. Dunn: Solder. \& Surf. Mont. Tech. 11 (1999) 27-35.

8) C. Hunt, L. Zou: Solder. \& Surf. Mont. Tech. 11 (1999) 36-43.

9) S. M. Hong, C. S. Kang and J. P. Jung: J. Electron. Mater. 31 (2002) 1104-1111.

10) J. Onuki, Y. Chonan, T. Komiyama and M. Nihei: Mater. Trans. 43 (2002) 1774-1777.

11) C. Lee, R. Gopalakrishnan, K. Nyunt, A. Wong, R. C. E. Tan and J. W.
L. Ong: Microelectronics Reliability. 39 (1997) 97.

12) L. Yang, J. B. Bernstein and K. C. Leong: IEEE Trans. Electron. 25 (2002) 91-99.

13) J. K. Moon, J. P. Jung and N. Y. Zhou: submitted.

14) ASTM-B32-00, Standard specification for solder metal, (2003).

15) W. Petasch, B. Kegel, H. Schmid, K. Lendenmann and H. U. Keller: Surf. Coat. Tech. 97 (1997) 176-181.

16) W. K. Choi, H. M. Lee: Scr. Mater. 46 (2002) 777-781.

17) K. H. Prakash and T. Sritharan: J. Electron. Mater. 32 (2003) 939-947.

18) Y. C. Chan, A. C. K. So and J. K. L. Lai: SMT solder joints, Mater. Sci. and Eng. B55 (1998) 5-13.

19) X. Ma, F. Wang, Y. Qian and F. Yoshida: Mater. Lett. 57 (2003) 33613365.

20) P. T. Vianco, K. L. Erickson and P. L. Hopkins: J. Electron. Mater. 23 (1994) 721-727.

21) N. Koopman, S. Nangalia, V. Rogers: Proc. 46th Electronic Components and Technology Conference. (1996) pp. 552-558. 